\title{
КОМПЛЕКС ПРОГРАММ ЭРГОНОМИЧЕСКОЙ ЭКСПЕРТИЗЫ ПРОТИВОШУМОВ
}

\begin{abstract}
Аннотация: Важным этапом ранних стадий жизненного цикла противошумов является их эргономическая экспертиза. Для ее обеспечения разработан комплекс программ, объединяющий пять программных комплексов, обеспечивающих интерактивный ввод значений эксплуатационно-технических и эргономических характеристик любых образчов индивидуально применяемыхпротивошумов (противошумные наушники, противошумные шлемы, противошумные вкладыши, средства защиты от воздушной акустической вибрации и др.), получаемых объективным (непосредственные измерения) и субъективным (анкетирование респондентов) способами, с последующим расчетом оченки интегрального показателя - коэффициента эргономичности в виде взвешенной свертки показателей. Методы исследования: системный анализ, обработка экспертной информации, эргономика, программирование, программная инженерия, эргономическая квалиметрия, информатика, кибернетика. За счет использования разработанных программ обеспечена стандартизачия прочедуры эргономической экспертизы средств индивидуальной защиты от авиачионного шума, создание и наполнение базы данных эргономических экспертиз (первичной информации и интегральных оченок), а, главное, своевременное выявление и устранение конструктивных недостатков, снижающихэргономичность разрабатываемых средств защиты, что, в итоге, повысило комфортность ихэксплуатации авиационными специалистами. Программные комплексы созданы на языке ActionScript (в среде Flash), имеют свидетельства о государственной регистрации.
\end{abstract}

Ключевые слова: эргономическая экспертиза, программный комплекс, защита от шума, акустическая эффективность, экспертная система, автоматизированная система, безопасность жизнедеятельности, взвешенная светрка показателей, эргономическая квалиметрия, программное обеспечение

Review: An important step in the early stages of the life cycle of hearing protectors is an ergonomic expertise. For its implementation a software complex was developed. It provide interactive input of values of operational, technical and economic characteristics of all samples of used individually hearing protectors (ear muffs, helmets, earplugs, protection against air acoustic vibrations and etc.), obtained using objective (direct measurements) and subjective (survey respondents) methods for further calculation of the integral index - the coefficient of ergonomics as a weighted convolution of indicators. Methods of the research: a systematic analysis, expert information processing, ergonomics, programming, software engineering, ergonomic qualimetry, computer science, cybernetics. By using the developed programs author provided standardization of the procedures 
of ergonomic examination of personal protective equipment from aircraft noise, creating and filling a database of economic expertise (with both primary information and integrated assessments) and most importantly timely detection and elimination of design flaws that reduce the usability of developed remedies, which, as a result, improved the comfort of their usage by aviation specialists. Software solutions are created using the ActionScript (Flash) and have the certificates of state registration.

Keywords: computer-aided system, expert system, acoustic efficiency, noise protection, software package, ergonomic expertise, life safety, weighted sum of indices, ergonomic qualimetry, software

Научно-технический прогресс способствует повышению мощности промышленного оборудования, сопровождающемуся увеличением неблагоприятных факторов условий деятельности персонала. Ведущее место среди таких факторов занимает шум: более двух миллионов россиян работают в условиях повышенного воздействия акустических колебаний (шума, инфразвука и ультразвука), около $25 \%$ рабочих мест персонала промышленности не соответствуют нормативам по шуму [1, 2]. Риски здоровью обусловливают снижение возраста выхода персонала промышленных предприятий на пенсию по состоянию здоровья, а, следовательно, и преждевременную потерю высококвалифицированных кадров. Риски работоспособности способствуют снижению надёжности профессиональной деятельности персонала, т.е. повышается вероятность ошибочных действий.

В большинстве случаев обеспечить акустическую безопасность персонала снижением уровня шума в источнике образования невозможно, так как снижение мощности оборудования снижает его производительность. В этом случае наиболее приемлемым способом повышения безопасности труда персонала являются технологии, обеспечивающие его защиту от шума. [9-13]. Названные обстоятельства обусловливают необходимость интенсификации исследований по разработке средств индивидуальной защиты от шума [14-17, 24-27]. Важным моментом является эргономическая экспертиза таких средств на ранних этапах их жизненного цикла: от обоснования необходимости разработки до изготовления и проведения предварительных и государственных испытаний опытных образцов.

Технология эргономической экспертизы должна отвечать следующим требованиям: методики анализа, применяемые для исследования эргономических характеристик должны быть взаимосогласованными; собираемые данные должны приводиться к унифицированному виду; все данные и результаты анализа должны накапливаться в единой базе данных [18-23, 28, 29]. Для обеспечения эргономической экспертизы средств индивидуальной защиты от авиационного шума разработан комплекс программ, объединяющих пять программных комплексов, которые можно применять как автономно, так и в составе единой автоматизированной системы.

При разработке математического обеспечения программ выполнялись следующие этапы [6-8, 18, 20-23]:

- формирование группы экспертов, обладающей высокими (более 0,7) коэффициен- 
тами компетентности, осведомленности и аргументированности, объединяющей эргономистов, инженеров, психологов, врачей и других специалистов;

- методом «мозгового штурма» формирование максимально полного перечня показателей, характеризующих эргономичность средства индивидуальной защиты;

- с помощью методов сокращения пространства признаков (отбора информативных признаков) формирование набора характеристик, описывающих эргономичность средства индивидуальной защиты с последующим утверждением группой экспертов;

- с помощью методов «круглого стола» формирование структуры интегрального показателя эргономичности с последующим ее утверждением группой экспертов;

- с помощью методов сбора и обработки экспертной информации определение весовых коэффициентов, позволяющих рассчитать сводные и интегральный показатель эргономичности как свертку первичных показателей;

- нормирование интегрального показателя эргономичности и разработка таблицы соответствий количественной (диапазонов изменения) и вербальной оценки интегрального показателя;

- реализация полученных результатов в виде программы и методик эргономической экспертизы с согласованием этих документов заказчиком разработки средства индивидуальной защиты.

\section{Алгоритм исследования акустической эффективности средств индивидуаль- ной защиты от шума}

Сущность разработанного алгоритма заключается в следующем.

1) Измеряют уровни звукового давления (УЗД) на рабочих местах специалистов, для которых предназначено средство индивидуальной защиты (СИЗ), на каждой октавной частоте с определением максимальных УЗД - УЗДтах

2) Для каждой нормируемой октавной частоты определяют значения требуемого снижения образцом СИЗ воздушной $\left(\Delta^{{ }^{6}}{ }_{\max }{ }^{\circ}\right.$, ДБ) и костной $\left(\Delta^{k}{ }_{\max }{ }^{\circ}{ }_{i}\right.$, ДБ) проводимости:

$$
\begin{gathered}
\Delta^{\beta}{ }_{\text {max } i}=\max \left\{0 ; У З Д \max _{i}-\Pi Д Y_{i}\right\}, \\
\Delta^{\kappa}{ }_{\text {max }}=\max \left\{0 ; \Delta^{6}{ }_{\max i}-20\right\},
\end{gathered}
$$

где ПДУ , дБ - предельно допустимый УЗД для соответствующей октавной частоты, установленный нормативными документами.

3) По величинам, полученным в п. 2, рассчитывают показатели, характеризующие акустическую эффективность СИЗ:

- Для шумозащитных наушников оценку коэффициента защиты $\left(k_{3}{ }^{\prime}\right)$ рассчитывают как логарифм от соотношения количества используемых октавных полос к сумме акустических эффективностей шумозащитных наушников в каждой используемой октавной полосе частот (в дБ): 


$$
k_{3}^{u}=20 \cdot \lg \frac{n}{\sum_{i=1}^{n} 10^{0,05 \Delta^{s} i}},
$$

где $n$ - количество используемых октавных полос, $\Delta^{{ }^{\beta}}{ }_{i}=\max \left\{0 ; \Delta^{\beta}{ }_{\max }-\Delta^{\mu}{ }_{i}\right\}$ - разность между требуемым и обеспечиваемым шумозащитными наушниками значением воздушной проводимости для каждой нормируемой октавной частоты, $\Delta^{\mu}{ }_{i}-$ значение акустической эффективности в подчашечном пространстве шумозащитных наушников для каждой анализируемой октавной частоты (указываемое в паспорте шумозащитных наушников если это значение в паспорте не указано, то его определяют экспериментально). Чем больше величина $k_{3}{ }^{\prime}$, тем лучше акустическая эффективность шумозащитных наушников.

- Для шумозащитного шлема оценку коэффициента защиты $\left(k_{3}{ }^{u}\right)$ рассчитывают как логарифм от соотношения количества используемых октавных полос к сумме акустических эффективностей образца шумозащитного шлема в каждой используемой октавной полосе частот (в дБ):

$$
k_{3}^{u}=20 \cdot \lg \frac{n}{\sum_{i=1}^{n} 10^{0,05 \Delta^{k}}{ }_{i}},
$$

где $n$ - количество используемых октавных полос, $\Delta^{\kappa}{ }_{i}=\max \left\{0 ; \Delta^{\kappa}{ }_{\operatorname{maxi}}-\Delta^{{ }^{u}}{ }_{i}\right\}$ - разность между требуемым и обеспечиваемым шумозащитным шлемом значением костной проводимости для каждой нормируемой октавной частоты, $\Delta^{w}{ }_{i}$ - значение акустической эффективности в подшлемном пространстве для каждой анализируемой октавной частоты (указываемое в паспорте шумозащитного шлема; если это значение в паспорте не указано, то его определяют экспериментально). Чем больше величина $k_{3}$, , тем лучше акустическая эффективность шумозащитного шлема.

- Для комбинации шумозащитного шлема с шумозащитными наушниками рассчитывают величину коэффициента $k_{3}$ :

$$
k_{3}=20 \cdot \lg \frac{2 n}{\sum_{i=1}^{n} 10^{0,05 \Delta^{s} i}+\sum_{i=1}^{n} 10^{0,05 \Delta_{i}^{\kappa}}} .
$$

Чем больше величина $k_{3}$, тем лучше акустическая эффективность комплекта шумозащитного шлема с шумозащитными наушниками.

\section{Алгоритм обработки информации для эргономической экспертизы противо- шумных наушников}

В соответствии с разработанной технологией автоматизированной поддержки эргономической экспертизы противошумных наушников в качестве объективных (непо- 
средственно измеряемых) характеристик используют эффективность защиты от шума для семи октавных частот: 125 Гц, 250 Гц, 500 Гц, 1000 Гц, 2000 Гц, 4000 Гц и 8000 Гц (хі i=1...7 - доля респондентов, у которых использование противошумных наушников не привело к снижению порогов слуха после смены на октавной частоте 125 Гц, 250 Гц, 500 Гц, 1000 Гц, 2000 Гц, 4000 Гц и 8000 Гц соответственно), а в качестве субъективных (получаемых анкетированием респондентов) характеристик используют:

- звон (шум) в ушах ( $x_{8}$ - доля респондентов, отметивших отсутствие звона (шума) в ушах),

- давление и тяжесть в ушах ( $x_{9}$ - доля респондентов, отметивших отсутствие давления и тяжести в ушах),

- головную боль ( $x_{10}$ - доля респондентов, отметивших отсутствие головной боли),

- шум и тяжесть в голове $\left(x_{11}\right.$ - доля респондентов, отметивших отсутствие шума и тяжести в голове),

- снижение работоспособности ( $x_{12}$ - доля респондентов, отметивших отсутствие снижения работоспособности),

- нарушение режима сна ( $x_{13}$ - доля респондентов, отметивших отсутствие нарушения режима сна),

- массогабаритные характеристики ( $x_{14}$ - доля респондентов, оценивших массогабаритные характеристики как «нормальные»),

- эффективность крепёжной системы ( $x_{15}$ - доля респондентов, оценивших эффективность крепёжной системы как «удовлетворительную»),

- удобство использования (комфортность) ( $x_{16}$ - доля респондентов, оценивших удобство использования (комфортность) как «удовлетворительную»),

- удобство хранения в неиспользуемом состоянии ( $x_{17}$ - доля респондентов, оценивших удобство хранения в неиспользуемом состоянии как «удовлетворительное»),

- качество оголовья ( $x_{18}$ - доля респондентов, оценивших качество оголовья как «удовлетворительное»),

- помехи профессиональной деятельности в противошумных наушниках $\left(x_{19}\right.$ - доля респондентов, отметивших отсутствие помех профессиональной деятельности в противошумных наушниках),

- безопасность использования ( $x_{20}$ - доля респондентов, оценивших безопасность использования как «удовлетворительную»),

- сочетаемость противошумных наушников с образцами экипировки $\left(x_{21}\right.$ - доля респондентов, оценивших сочетаемость противошумных наушников с образцами экипировки как «удовлетворительную»),

- неприятные ощущения в околоушной области $\left(x_{22}\right.$ - доля респондентов, отметивших отсутствие неприятных ощущений в околоушной области),

- покраснение кожи в околоушной области ( $x_{23}$ - доля респондентов, отметивших отсутствие покраснения кожи в околоушной области),

- достаточность снижения шума ( $x_{24}$ - доля респондентов, оценивших степень снижения шума противошумными наушниками как достаточную), и на основе полученных 
оценок рассчитывают коэффициент эргономичности противошумных наушников

$$
\begin{gathered}
k=7 x_{1}+7 x_{2}+7 x_{3}+7 x_{4}+7 x_{5}+5 x_{6}+5 x_{7}+4 x_{8}+5 x_{9}+3 x_{10}+4 x_{11}+ \\
+2 x_{12}+2 x_{13}+3 x_{14}+4 x_{15}+4 x_{16}+2 x_{17}+2 x_{18}+2 x_{19}+3 x_{20}+ \\
+2 x_{21}+5 x_{22}+5 x_{23}+3 x_{24}
\end{gathered}
$$

по величине которого оценивают эргономический уровень противошумных наушников как низкий $(k<40)$; удовлетворительный $(40 \leq k<70)$, хороший $(70 \leq k<90)$ или отличный $(k \geq 90)$

Алгоритмы обработки информации для эргономической экспертизы противошумных вкладышей и противошумных шлемов построены по аналогичной схеме и отличаются названием некоторых показателей и весовыми коэффициентами, используемыми для расчета интегрального показателя - коэффициента эргономичности.

\section{Алгоритм обработки информации для эргономической экспертизы средств индивидуальной противошумной виброзащиты}

Для автоматизированной поддержки эргономической экспертизы противошумных виброзащитных поясов, жилетов, комбинезонов и костюмов, предназначенных для использования специалистами, подвергающимися воздействию авиационного шума, в качестве объективных характеристик используют:

- снижение вибротактильной чувствительности, обусловленное использованием средства индивидуальной защиты ( $y_{1}$ - доля респондентов, у которых не отмечено снижение вибротактильной чувствительности после использования средства индивидуальной защиты в течение смены),

- состояние кожи человека под средством индивидуальной защиты ( $y_{2}$ - доля респондентов, у которых отмечено отсутствие покраснения кожи после использования средства индивидуальной защиты в течение смены),

- влажность кожных покровов человека под средством индивидуальной защиты ( $y_{3}$ - доля респондентов, влажность кожных покровов которых оценена как «нормальная»);

в качестве субъективных характеристик используют:

- массогабаритные характеристики средства индивидуальной защиты ( $y_{4}$ - доля респондентов, оценивших массогабаритные характеристики как «удовлетворительные»),

- эффективность крепёжной системы средства индивидуальной защиты ( $y_{5}$ - доля респондентов, оценившихэффективность крепёжной системы как «удовлетворительная»),

- удобство (комфортность) использования средства индивидуальной защиты ( $y_{6}$ доля респондентов, оценивших удобство (комфортность) использования как «удовлетворительное»);

- удобство хранения средства индивидуальной защиты в неиспользованном состоянии ( $y_{7}$ - доля респондентов, оценивших удобство хранения в неиспользованном состоянии как «удовлетворительное»), 
- отсутствие помех профессиональной деятельности в средстве индивидуальной защиты ( $y_{8}$ - доля респондентов, отметивших отсутствие помех профессиональной деятельности с использованием средства индивидуальной защиты),

- безопасность использования средства индивидуальной защиты ( $y_{9}$ - доля респондентов, оценивших безопасность использования как «удовлетворительную»),

- сочетаемость средства индивидуальной защиты с другими элементами экипировки $\left(y_{10}\right.$ - доля респондентов, оценивших сочетаемость средства индивидуальной защиты с образцами экипировки как «удовлетворительная»),

- неприятные ощущения при использовании средства индивидуальной защиты ( $y_{11}$ - доля респондентов, отметивших отсутствие неприятных ощущений, вызванных использованием средства индивидуальной защиты),

- защитные свойства средства индивидуальной защиты ( $y_{12}$ - доля респондентов, отметивших высокие защитные свойства средства индивидуальной защиты),

- удобство одевания/съема средства индивидуальной защиты ( $y_{13}$ - доля респондентов, оценивших удобство одевания/съема средства индивидуальной защиты как «удовлетворительно»), и на основе полученных оценок рассчитывают коэффициент эргономичности средства индивидуальной защиты человека от воздушной акустической вибрации

$$
\begin{gathered}
k e=0,15 y_{1}+0,13 y_{2}+0,04 y_{3}+0,07 y_{4}+0,1 y_{5}+0,1 y_{6}+ \\
+0,02 y_{7}+0,12 y_{8}+0,1 y_{9}+0,03 y_{10}+0,05 y_{11}+0,04 y_{12}+0,05 y_{13},
\end{gathered}
$$

по величине которого оценивают эргономичность средств индивидуальной защиты человека от воздушной акустической вибрации как низкую $(k e<0,4)$; удовлетворительную $(0,4 \leq k e<0,7)$, хорошую $(0,7 \leq k e<0,9)$ или отличную $(k e \geq 0,9)$

\section{Программное обеспечение эргономической экспертизы противошумов}

После выполнения изложенных этапов осуществлялась разработка программы (автоматизированной системы), обеспечивающей сбор и обработку информации в интересах эргономической экспертизы средства индивидуальной защиты. Автором разработаны пять программных комплексов [1-5]:

1. Автоматизированная система исследования акустической эффективности средств индивидуальной защиты от шума, предназначенная для автоматизации сбора и обработки информации при исследовании акустической эффективности любых образцов средств индивидуальной защиты от шума во всем диапазоне частот, заданном санитарными нормами (2 Гц ... 8 кГц) [1].

2. Автоматизированная система эргономической экспертизы противошумных наушников, предназначенная для автоматизации сбора и обработки информации при проведении их эргономической экспертизы в интересах обоснования, исследования и совершенствования эксплуатационно-технических и эргономических характеристик противошумных наушников, применяемых авиационными специалистами [3].

3. Автоматизированная система эргономической экспертизы противошумных 
вкладышей, предназначенная для автоматизации сбора и обработки информации при проведении их эргономической экспертизы в интересах обоснования, исследования и совершенствования эксплуатационно-технических и эргономических характеристик противошумных вкладышей, применяемых авиационными специалистами [4].

4. Автоматизированная система эргономической экспертизы противошумного шлема, предназначенная для автоматизации сбора и обработки информации при проведении его эргономической экспертизы, в интересах обоснования, исследования и совершенствования эксплуатационно-технических и эргономических характеристик противошумного шлема, применяемого авиационными специалистами [2].

5. Автоматизированная система эргономической экспертизы средств индивидуальной противошумной виброзащиты (поясов, жилетов, комбинезонов и костюмов), предназначенная для автоматизации сбора и обработки информации при проведении их эргономической экспертизы в интересах обоснования, исследования и совершенствования эксплуатационно-технических и эргономических характеристик средств индивидуальной противошумной виброзащиты, применяемых авиационными специалистами [5].

Функциональные возможности разработанных программ обеспечивают интерактивный ввод значений эксплуатационно-технических и эргономических характеристик средств индивидуальной защиты от шума, получаемых объективным (непосредственные измерения) и субъективным (анкетирование респондентов) способами, с последующим расчетом оценки интегрального показателя - коэффициента эргономичности (изменяется в диапазоне от «0» до «1»).

Интерфейс ввода первичных показателей автоматизированной системы исследования акустической эффективности средств индивидуальной защиты от шума реализован в виде диалогового окна, предусматривающего занесение значений характеристик в поля таблицы, а для остальных программ - в виде диалогового окна, предусматривающего выбор одного из вариантов ответа на вопрос.

Разработанные программные комплексы созданы на языке ActionScript (в cpeде Flash), предназначены для IBM PC-совместимых компьютеров и реализованы при проведении теоретико-экспериментальных исследований по формированию тактико-технических требований к средствам защиты от авиационного шума и при проведении предварительных и государственных испытаний более 10 образцов таких средств на всех этапах их жизненного цикла.

Результаты эргономической экспертизы представляются в виде типовой экранной формы (рис. 1) [1-5]. 


\begin{tabular}{|c|c|c|}
\hline \multicolumn{3}{|c|}{$\begin{array}{c}\text { Автоматизированная система эргономической экспертизы } \\
\text { противошумных наушников } \\
\text { Оцениваемый образец - АВБ-11-76/4 } \\
\text { Результаты обработки обследований } 4 \text { респондентов }\end{array}$} \\
\hline Первичные показатели: & & Оценка \\
\hline $\begin{array}{l}\text { По результатам тональной аудиометрии использование СИз не } \\
\text { привело к снижению порогов слуха на следующих частотах: }\end{array}$ & & \\
\hline - октавная частота 125 Гц: & $n=4$ & 0.5 \\
\hline - октавная частота 250 Гц: & $n=4$ & 0.5 \\
\hline - октавная частота 500 Гц: & $\mathrm{n}=4$ & 0.75 \\
\hline - октавная частота 1000 Гц: & $n=3$ & 0.67 \\
\hline - октавная частота 2000 Гц: & $\mathrm{n}=4$ & 0.75 \\
\hline - октавная частота 4000 Гц: & $n=3$ & 1 \\
\hline - октавная частота 8000 Гц: & $\mathrm{n}=4$ & 0.25 \\
\hline Звон/шум в ушах отсутствует: & $\mathrm{n}=4$ & 0.75 \\
\hline Давление и тяжесть в ушах отсутствуют: & $n=4$ & 0.75 \\
\hline Головная боль отсутствует: & $n=4$ & 1 \\
\hline Шум и тяжесть в голове отсутствуют: & $n=4$ & 0.5 \\
\hline Снижение работоспособности отсутствует: & $\mathrm{n}=4$ & 0.75 \\
\hline Нарушение режима сна отсутствует: & $\mathrm{n}=4$ & 0.75 \\
\hline Массогабаритные характеристики сиз "нормальные": & $n=4$ & 1 \\
\hline Эффективность крепежной системы СИз удовлетворительная: & $\mathrm{n}=4$ & 0.75 \\
\hline Удобство использования/комфортность СИЗ удовлетворительная: & $n=4$ & 0.5 \\
\hline Удобство хранения неиспользуемого СИЗ удовлетворительное: & $\mathrm{n}=2$ & 0.5 \\
\hline Качество оголовья СИЗ удовлетворительное: & $\mathrm{n}=3$ & 1 \\
\hline Помехи профессиональной деятельности в СИЗ отсутствуют: & $\mathrm{n}=2$ & 1 \\
\hline Безопасность использования СИз удовлетворительная: & $\mathrm{n}=4$ & 0.5 \\
\hline Сочетаемость СИЗ с образцами экипировки удовлетворительная: & $\mathrm{n}=4$ & 1 \\
\hline Неприятные ощущения в околоушной области отсутсвуют: & $\mathrm{n}=4$ & 0.5 \\
\hline Покраснение кожи в околоушной области отсутствует: & $n=4$ & 0.5 \\
\hline Степень снижения шума наушниками достаточная: & $\mathrm{n}=4$ & 0.75 \\
\hline \multicolumn{3}{|l|}{ Комплексные показатели: } \\
\hline Объективная оценка эффективности & & 0.64 \\
\hline Суб̆ъективная оценка эффектиности & & 0.65 \\
\hline Субъъективная оценка эксплуатационных характеристик & & 0.75 \\
\hline \multirow[t]{2}{*}{ Коэфффициент эргономичности } & & 0.67 \\
\hline & & $\begin{array}{l}\text { Эргономичность образца } \\
\text { удовлетворительная }\end{array}$ \\
\hline
\end{tabular}

Рис. 1. Экранная форма результата эргономической экспертизы. 
За счет использования разработанных программ обеспечена стандартизация процедуры эргономической экспертизы средств индивидуальной защиты от авиационного шума, создание и наполнение базы данных эргономических экспертиз (первичной информации и интегральных оценок), а, главное, своевременное выявление и устранение конструктивных недостатков, снижающих эргономичность разрабатываемых средств защиты, что, в итоге, повысило комфортность их эксплуатации авиационными специалистами.

\section{Библиография :}

1. Автоматизированная система исследования акустической эффективности средств индивидуальной защиты от шума: свидетельство о государственной регистрации программы для ЭВМ № 2014612091 / Н.И.Скуратовский [и др.]. 2013. 1 с.

2. Автоматизированная система эргономической экспертизы противошумного шлема: свидетельство о государственной регистрации программы для ЭВМ № 2013660986 / Н.И.Скуратовский [и др.]. 2013. 1 с.

3. Автоматизированная система эргономической экспертизы противошумных наушников: свидетельство 0 государственной регистрации программы для ЭВМ № 2013661051 / Н.И.Скуратовский [и др.]. 2013. 1 с.

4. Автоматизированная система эргономической экспертизы противошумных вкладышей: свидетельство 0 государственной регистрации программы для ЭВМ № 2013661051 / Н.И.Скуратовский [и др.]. 2013. 1 с.

5. Автоматизированная система эргономической экспертизы средств индивидуальной противошумной виброзащиты: свидетельство о государственной регистрации программы для ЭВМ / Н.И.Скуратовский [и др.]. 2013. 1 с.

6. Богомолов А.В., Драган С.П. Автоматизированный мониторинг и технологии обеспечения акустической безопасности персонала // Автоматизация. Современные технологии. 2015. №4. С. 25-29.

7. Богомолов А.В., Кукушкин Ю.А. Автоматизация персонифицированного мониторинга условий труда // Автоматизация. Современные технологии. 2015. №3. С. 6-8.

8. Богомолов А.В., Скуратовский Н.И., Драган С.П., Сомов М.В. Методика эргономической экспертизы противошумных наушников // Инженерный вестник. 2013. №9. С. 8.

9. Жданько И.М., Зинкин В.Н., Солдатов С.К., Богомолов А.В., Шешегов П.М. Фундаментальные и прикладные аспектыпрофилактики неблагоприятногодействияавиационного шума// Авиакосмическаяи экологическая медицина. 2014. Т. 48. № 4. С. 5-16.

10. Зинкин В.Н., Ахметзянов И.М., Драган С.П., Богомолов А.В. Особенности сочетанного действия шума и инфразвука на организм // Безопасность жизнедеятельности. 2011. № 9. С. 2-10.

11. Зинкин В.Н., Ахметзянов И.М., Солдатов С.К., Богомолов А.В. Медико-биологическая оценка эффективности средств индивидуальной защиты от шума // Медицина труда и промышленная экология. 2011. № 4. С. 33-34. 
12. Зинкин В.Н., Богомолов А.В., Драган С.П., Ахметзянов И.М. Анализ рисков здоровью, обусловленных сочетанным действием шума и инфразвука // Проблемы анализа риска. 2011. Т. 8. № 4. С. 82-92.

13. Зинкин В.Н., Богомолов А.В., Драган С.П., Ахметзянов И.М. Кумулятивные медико-экологические эффекты сочетанного действия шума и инфразвука // Экология и промышленность России. 2012. № 3. С. 46-49.

14. Зинкин В.Н., Солдатов С.К., Богомолов А.В., Драган С.П. Актуальные проблемы защиты населения от низкочастотного шума и инфразвука // Технологии гражданской безопасности. 2015. Т. 12. № 1. С. 90-96.

15. Зинкин В.Н., Солдатов С.К., Богомолов А.В., Кукушкин Ю.А., Ахметзянов И.М., Шешегов П.М. Авиационный шум как фактор эколого-социального неблагополучия // Проблемы безопасности полетов. 2010. № 10. С. 3-13.

16. Зинкин В.Н., Солдатов С.К., Богомолов А.В., Кукушкин Ю.А., Ахметзянов И.М., Шешегов П.М. Риски здоровью, обусловленные кумулятивным действием авиационного шума, и мероприятия по борьбе с ним // Проблемы безопасности и чрезвычайных ситуаций. 2011. № 1. С. 80-88.

17. Зинкин В.Н., Солдатов С.К., Богомолов А.В., Шведов А.П. Обоснование использования специалистами средств индивидуальной защиты при воздействиии авиационного шума // Информатика и системы управления. 2009. № 4. С. 139-141.

18. Козлов В.Е., Богомолов А.В., Рудаков С.В., Оленченко В.Т. Математическое обеспечение обработки рейтинговой информации в задачах экспертного оценивания // Мир измерений. 2012. № 9. С. 42-49.

19. Падерно П.И. Эргономическая экспертиза: теория и практика, проблемы и трудности // Человеческий фактор: проблемы психологии и эргономики. 2007. № 3. С. 122-124.

20. Скуратовский Н.И. Алгоритмы и программы эргономической экспертизы противошумов // Алгоритмы, методы и системы обработки данных. 2014. № 1 (26). С. 48-60.

21. Скуратовский Н.И. Методика расчёта коэффициента эргономичности средств индивидуальной защиты от авиационного шума // Проблемы безопасности полетов. 2013. № 12. С. 50-54.

22. Скуратовский Н.И. Технология эргономической экспертизы средств индивидуальной защиты от авиационного шума // Технологии техносферной безопасности. 2013. № 6 (52). С. 24.

23. Скуратовский Н.И., Зинкин В.Н., Богомолов А.В. Автоматизированная поддержка эргономической экспертизы средств индивидуальной защиты от авиационного шума // Человеческий фактор: проблемы психологии и эргономики. 2014. № 1 (68). С. 54-57.

24. Солдатов С.К., Богомолов А.В., Зинкин В.Н., Аверьянов А.А., Россельс А.В., Пацкин Г.А., Соколов Б.А. Средства и методы защиты от авиационного шума: состояние и перспективы развития // Авиакосмическая и экологическая медицина. 2011. Т. 45. № 5. С. 3-11.

25. Солдатов С.К., Богомолов А.В., Зинкин В.Н., Драган С.П. Проблемы обеспечения акустической безопасности персонала авиационной промышленности // Безопасность труда в промышленности. 2014. № 10. С. 58-60.

26. Солдатов С.К., Кукушкин Ю.А., Зинкин В.Н., Богомолов А.В., Кирий С.В., Шешегов П.М., Шишкин 0.Ю., Казачков В.В. Методическое обеспечение оценивания и прогнозирования работоспособности операторов, подвергающихся воздействию авиационного шума // Безопасность жизнедеятельности. 2006. № 4. С. 11-20.

27. Солдатов С.К., Скуратовский Н.И. Инженерно-технические аспекты эволюции средств защиты от авиационного шума // Технологии техносферной безопасности. 2013. № 6 (52). С. 23. 
28. Солнцев В.И., Сомов М.В., Скуратовский Н.И. Автоматизация эргономических экспертиз средств защиты от шума // Программные системы и вычислительные методы.-2014.-№4.-С. 446-455. DOI: 10.7256/2305-6061.2014.4.14054.URL: http://www.nbpublish.com/go_to_article.php?id=31885

29. Ушаков И.Б., Богомолов А.В., Кукушкин Ю.А. Принципы организации контроля и оптимизации функционального состояния операторов // Безопасность жизнедеятельности. 2006. № 1. С. 4-10

\section{References:}

1. Avtomatizirovannaya sistema issledovaniya akusticheskoi effektivnosti sredstv individual'noi zashchity ot shuma: svidetel'stvo o gosudarstvennoi registratsii programmy dlya EVM № 2014612091 / N.I.Skuratovskii [i dr.]. 2013. 1 s.

2. Avtomatizirovannaya sistema ergonomicheskoi ekspertizy protivoshumnogo shlema: svidetel'stvo o gosudarstvennoi registratsii programmy dlya EVM № 2013660986 / N.I.Skuratovskii [i dr.]. 2013. 1 s.

3. Avtomatizirovannaya sistema ergonomicheskoi ekspertizy protivoshumnykh naushnikov: svidetel'stvo o gosudarstvennoi registratsii programmy dlya EVM № 2013661051 / N.I.Skuratovskii [i dr.]. 2013. 1 s.

4. Avtomatizirovannaya sistema ergonomicheskoi ekspertizy protivoshumnykh vkladyshei: svidetel'stvo o gosudarstvennoi registratsii programmy dlya EVM № 2013661051 / N.I.Skuratovskii [i dr.]. 2013. 1 s.

5. Avtomatizirovannaya sistema ergonomicheskoi ekspertizy sredstv individual'noi protivoshumnoi vibrozashchity: svidetel'stvo o gosudarstvennoi registratsii programmy dlya EVM / N.ISkuratovskii [i dr.]. 2013. 1 s.

6. Bogomolov A.V., Dragan S.P. Avtomatizirovannyi monitoring i tekhnologii obespecheniya akusticheskoi bezopasnosti personala // Avtomatizatsiya. Sovremennye tekhnologii. 2015. №4. S. 25-29.

7. Bogomolov A.V., Kukushkin Yu.A. Avtomatizatsiya personifitsirovannogo monitoringa uslovii truda // Avtomatizatsiya. Sovremennye tekhnologii. 2015. № 3. S. 6-8.

8. Bogomolov A.V., Skuratovskii N.I., Dragan S.P., Somov M.V. Metodika ergonomicheskoi ekspertizy protivoshumnykh naushnikov // Inzhenernyi vestnik. 2013. №9. S. 8.

9. Zhdan'ko I.M., Zinkin V.N., Soldatov S.K., Bogomolov A.V., Sheshegov P.M. Fundamental'nye i prikladnye aspekty profilaktiki neblagopriyatnogo deistviya aviatsionnogo shuma // Aviakosmicheskaya i ekologicheskaya meditsina. 2014. T. 48. № 4. S. 5-16.

10. Zinkin V.N., Akhmetzyanov I.M., Dragan S.P., Bogomolov A.V. Osobennosti sochetannogo deistviya shuma i infrazvuka na organizm // Bezopasnost' zhiznedeyatel'nosti. 2011. № 9. S. 2-10.

11. Zinkin V.N., Akhmetzyanov I.M., Soldatov S.K., Bogomolov A.V. Mediko-biologicheskaya otsenka effektivnosti sredstv individual'noi zashchity ot shuma // Meditsina truda i promyshlennaya ekologiya. 2011. № 4. S. 33-34.

12. Zinkin V.N., Bogomolov A.V., Dragan S.P., Akhmetzyanov I.M. Analiz riskov zdorov'yu, obuslovlennykh sochetannym deistviem shuma i infrazvuka // Problemy analiza riska. 2011. T. 8. № 4. S. 82-92.

13. Zinkin V.N., Bogomolov A.V., Dragan S.P., Akhmetzyanov I.M. Kumulyativnye mediko-ekologicheskie effekty sochetannogo deistviya shuma i infrazvuka // Ekologiya i promyshlennost' Rossii. 2012. № 3. S. 46-49.

14. Zinkin V.N., Soldatov S.K., Bogomolov A.V., Dragan S.P. Aktual'nye problemy zashchity naseleniya ot nizkochastotnogo shuma i infrazvuka // Tekhnologii grazhdanskoi bezopasnosti. 2015. T. 12. № 1. S. 90-96.

15. Zinkin V.N., Soldatov S.K., Bogomolov A.V., Kukushkin Yu.A., Akhmetzyanov I.M., Sheshegov P.M. Aviatsionnyi shum kak faktor ekologo-sotsial'nogo neblagopoluchiya // Problemy bezopasnosti poletov. 2010. № 10. S. 3-13. 
16. Zinkin V.N., Soldatov S.K., Bogomolov A.V., Kukushkin Yu.A., Akhmetzyanov I.M., Sheshegov P.M. Riski zdorov'yu, obuslovlennye kumulyativnym deistviem aviatsionnogo shuma, i meropriyatiya po bor'be s nim // Problemy bezopasnosti i chrezvychainykh situatsii. 2011. № 1. S. 80-88.

17. Zinkin V.N., Soldatov S.K., Bogomolov A.V., Shvedov A.P. Obosnovanie ispol'zovaniya spetsialistami sredstv individual'noi zashchity pri vozdeistviii aviatsionnogo shuma // Informatika i sistemy upravleniya. 2009. № 4. S. 139-141.

18. Kozlov V.E., Bogomolov A.V., Rudakov S.V., Olenchenko V.T. Matematicheskoe obespechenie obrabotki reitingovoi informatsii v zadachakh ekspertnogo otsenivaniya // Mir izmerenii. 2012. № 9. S. 42-49.

19. Paderno P.I. Ergonomicheskaya ekspertiza: teoriya i praktika, problemy i trudnosti // Chelovecheskii faktor: problemy psikhologii i ergonomiki. 2007. № 3. S. 122-124.

20. Skuratovskii N.I. Algoritmy i programmy ergonomicheskoi ekspertizy protivoshumov // Algoritmy, metody i sistemy obrabotki dannykh. 2014. № 1 (26). S. 48-60.

21. Skuratovskii N.I. Metodika rascheta koeffitsienta ergonomichnosti sredstv individual'noi zashchity ot aviatsionnogo shuma // Problemy bezopasnosti poletov. 2013. № 12. S. 50-54.

22. Skuratovskii N.I. Tekhnologiya ergonomicheskoi ekspertizy sredstv individual'noi zashchity ot aviatsionnogo shuma // Tekhnologii tekhnosfernoi bezopasnosti. 2013. № 6 (52). S. 24.

23. Skuratovskii N.I., Zinkin V.N., Bogomolov A.V. Avtomatizirovannaya podderzhka ergonomicheskoi ekspertizy sredstv individual'noi zashchity ot aviatsionnogo shuma // Chelovecheskii faktor: problemy psikhologii i ergonomiki. 2014. № 1 (68). S. 54-57.

24. Soldatov S.K., Bogomolov A.V., Zinkin V.N., Aver'yanov A.A., Rossel's A.V., Patskin G.A., Sokolov B.A. Sredstva i metody zashchity ot aviatsionnogo shuma: sostoyanie i perspektivy razvitiya // Aviakosmicheskaya i ekologicheskaya meditsina. 2011. T. 45. № 5. S. 3-11.

25. Soldatov S.K., Bogomolov A.V., Zinkin V.N., Dragan S.P. Problemy obespecheniya akusticheskoi bezopasnosti personala aviatsionnoi promyshlennosti // Bezopasnost' truda v promyshlennosti. 2014. № 10. S. 58-60.

26. Soldatov S.K., Kukushkin Yu.A., Zinkin V.N., Bogomolov A.V., Kirii S.V., Sheshegov P.M., Shishkin 0.Yu., Kazachkov V.V. Metodicheskoe obespechenie otsenivaniya i prognozirovaniya rabotosposobnosti operatorov, podvergayushchikhsya vozdeistviyu aviatsionnogo shuma // Bezopasnost' zhiznedeyatel'nosti. 2006. № 4. S. 11-20.

27. Soldatov S.K., Skuratovskii N.I. Inzhenerno-tekhnicheskie aspekty evolyutsii sredstv zashchity ot aviatsionnogo shuma // Tekhnologii tekhnosfernoi bezopasnosti. 2013. № 6 (52). S. 23.

28. Solntsev V.I., Somov M.V., Skuratovskii N.I. Avtomatizatsiya ergonomicheskikh ekspertiz sredstv zashchity ot shuma // Programmnye sistemy i vychislitel'nye metody.-2014.-№4.-C. 446-455. DOI: 10.7256/2305-6061.2014.4.14054. URL: http://www.nbpublish.com/go_to_article.php?id=31885

29. Ushakov I.B., Bogomolov A.V., Kukushkin Yu.A. Printsipy organizatsii kontrolya i optimizatsii funktsional'nogo sostoyaniya operatorov // Bezopasnost' zhiznedeyatel'nosti. 2006. № 1. S. 4-10. 